Connotas. Revista de crítica y teoría literarias 
CONNOTAS. REVISTA DE CRÍTICA Y TEORÍA LITERARIAS. Enero - diciembre 2013, es una publicación anual editada por la Universidad de Sonora, a través de la División de Humanidades y Bellas Artes, en el Departamento de Letras y Lingüística. Blvd. Luis Encinas y Blvd. Rosales s/n, Col. Centro, C.P. 83000, Hermosillo Sonora; Tel. (662) 2592 136, (662) 2592 157, <www.uson.mx>, <http://www.connotas.uson.mx, connotas@capomo.uson.mx>. Editor responsable: Rosario Fortino Corral Rodríguez. Reservas de Derechos al Uso Exclusivo núm. 04-2006-020714184900-102. ISSN: 18706630; ambos otorgados por el Instituto Nacional del Derecho de Autor. Licitud de Título núm. 13434 y de Contenido núm. 11007, otorgados por la Comisión Calificadora de Publicaciones y Revistas Ilustradas de la Secretaría de Gobernación. Este libro se publicó con el apoyo del Programa Integral de Fortalecimiento Institucional C/PIFI 2013-12934

Se autoriza la reproducción total o parcial de los contenidos de la presente publicación, siempre y cuando se acredite adecuadamente el origen de los mismos.

Datos de contacto para la publicación: División de Humanidades y Bellas Artes, Departamento de Letras y Lingüística; Apartado Postal 793, Col. Centro, C.P. 83000, Hermosillo, Sonora, México. Tels.: (662) 259-21-87, Tel-fax 212-55-29. Correo electrónico: connotas@capomo.uson.mx Página web: http://www.connotas.uson.mx 


\section{Connotas. Revista de crítica y teoría literarias}

Núm. 13, año 2013

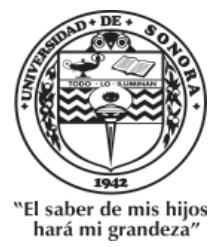


UNIVERSIDAD DE SONORA

RECTOR

Heriberto Grijalva Monteverde

VICERRECTORA

Arminda Guadalupe García de León Peñúñuri

Secretario General Académico

Enrique Fernando Velázquez Contreras

División de Humanidades y Bellas Artes

María Rita Plancarte Martínez

Departamento de Letras y LingÜística

Ana Bertha de la Vara Estrada

César Avilés Icedo

Rosa María Burrola Encinas

Fortino Corral Rodríguez

Leticia Martínez Figueroa

Jesús Abad Navarro Gálvez

Gabriel Osuna Osuna

María Rita Plancarte Martínez

DiRECTOR

Fortino Corral Rodríguez

Giuseppe Bellini

Consejo InTERnacional

Universidad de Milán

Carlos Pacheco

Luis Beltrán Almería

Universidad Simón Bolivar

Universidad de Zaragoza

Rafael Olea Franco

Helena Beristáin

El Colegio de México

Joan Oleza Simó

Universidad Nacional Autónoma de México

Universidad de Valencia

Raúl Bueno-Chávez

Dartmouth College

Julio Ortega

Evodio Escalante

Brown University

Luz Aurora Pimentel

Universidad Autónoma Metropolitana

Universidad Nacional Autónoma de México

Beatriz González-Stephan

Susana Reisz

Rice University

Aníbal González

The City University of New York.

José Carlos Rovira

Universidad de Alicante

Yale University

Aurelio González Pérez

Charles Tatum

El Colegio de México

Yvette Jiménez de Báez

The University of Arizona

Jorge Urrutia

El Colegio de México

Universidad Carlos III de Madrid

Nelson Osorio Tejeda

Universidad de Santiago de Chile

Emil Volek

Arizona State University 


\section{Índice}

\section{Artículos}

Una hermenéutica analógica para la literatura

Mauricio Beuchot Puente

La obra de Jorge Luis Borges durante la década de 1930: estudio de algunos elementos para la conformación de su poética en Discusión (1932)

Daniel Zavala Medina

Metáforas de la locura y la muerte en "Río subterráneo" de Inés Arredondo

Gabriel Osuna Osuna

La alteridad como vector de la construcción del yo: La muerte me da de Cristina Rivera Garza y El Gran Vidrio de Mario Bellatin Véronique Pitois Pallares

Uno soñaba que era rey de Enrique Serna: un espacio de contradicción Claudia Gidi

Una angustia compartida. Análisis de la voz narrativa en Mi hermano Carlos de Jorge López Páez

Jorge Antonio Muñoz Figueroa

De Los perros románticos y otros poemas de Roberto Bolaño Marina Martínez Andrade 
Las novelas del Crack, multiplicidad y superposición de mundos Ramón Alvarado Ruiz

La construcción del “otro" en la Relación de la jornada de Cíbola de Pedro Castañeda de Nájera

Guillermo Martínez Sotelo

Destino e historia en Margarita, está linda la mar de Sergio Ramírez

María Rita Plancarte Martínez

\section{Notas}

Identidad negada y mundo al revés en Santa María del Circo de David Toscana

César Avilés Icedo y María Elena González Borgaro 203

"El buen ejemplo" de Vicente Riva Palacio: la historia de un cuento

Marco Antonio Chavarín González

Organización descriptiva en Catarina de San Juan, princesa de la India y visionaria de Puebla

Silvia Guadalupe Alarcón Sánchez

Genealogías en Todo aqui es polvo de Esther Seligson. Lectura a partir de los epígrafes

Luz Elena Zamudio Rodríguez

\section{Reseñas}

Martha Elena Munguía Zatarain. La risa en la literatura mexicana (apuntes de poética)

Silvia Alicia Manzanilla Sosa 
Véronique Pitois-Pallares. El arte del fragmento: El Gran Vidrio de Mario Bellatin

Julio César Zárate Ramírez 255

Nicolás Kanellos. Hispanic Immigrant Literature: El sueño del retorno Josué Gutiérrez González

Dante Salgado. Brevísima relación de la idea de amor en Occidente Diana Vanessa Geraldo Camacho 271

Mara L. García. Paco Yunque: una mirada crítica Juan Paredes Carbonell 279

Abstracts 283

Résumés

Normas editoriales 



\title{
Una hermenéutica analógica para la literatura
}

\author{
Mauricio Beuchot Puente*
}

Resumen:

Este artículo expone las bases de una hermenéutica analógica precisando las relaciones entre los conceptos que la fundamentan (iconicidad, analogía, símbolo, metonimia, metáfora, interpretación, univocidad, equivocidad). Ampliando las nociones de teóricos como Jakobson y Ricoeur, esta hermenéutica propone un balance interpretativo que participe de lo metonímico y lo metafórico, de lo literal y lo alegórico. Entre la hermenéutica univocista de los positivismos y la hermenéutica equivocista de los posmodernismos, la hermenéutica analógica apela al equilibrio proporcional de la analogía, base de la phrónesis de los griegos, y se proyecta como una oportuna alternativa frente a la crisis cultural derivada del uso exclusivista de los enfoques polarizados.

Palabras clave:

Hermenéutica, analogía, univocismo, equivocismo.

\section{Introducción}

En estas páginas deseo mostrar la fecundidad que puede tener una hermenéutica vertebrada por la noción de analogía para la literatura. Lo haré señalando la eficiencia que alcanza al hacernos comprender la estructura y la función de la metáfora, la cual se contrasta con la

\footnotetext{
* Universidad Nacional Autónoma de México.
} 
metonimia. Ambas juegan un papel primordial en la literatura, tanto en la poesía como en la prosa.

Comenzaré abordando, en estas páginas, la naturaleza de dicha hermenéutica analógica, frente a la interpretación de la metáfora, que es como la del símbolo. En eso resplandecerá su carácter analógico e icónico, esto es, la relación de la iconicidad con la analogía. Y es que, como es claro, el símbolo es un aspecto muy relevante de nuestro ser cultural, de personas que vivimos y actuamos en una cultura. Para la cuestión de la metáfora y el símbolo, acudiré a las esclarecedoras explicaciones de Paul Ricoeur (1913-2005). Además, trataré de hacer ver que una hermenéutica analógica puede ser un buen instrumento para interpretar la metáfora y el símbolo. Una hermenéutica analógica está basada en la noción de analogía, muy antigua aunque, también, muy actual.

La analogía va más allá de la mera semejanza, y tiene la metáfora y la metonimia como aspectos o polos, con lo cual puede aplicarlas a los textos en la interpretación, de camino a una hermenéutica analógica. Sobre todo la metáfora, pero también la metonimia, al ser aspectos de la analogía, son también aspectos del símbolo, el cual es sumamente analógico. Por eso veremos, finalmente, cómo se aplica esto al símbolo.

\section{La hermenéutica analógica}

Comenzaré, aludiendo brevemente a las principales características de una hermenéutica analógica. La hermenéutica es una teoría de la interpretación de textos, y la hermenéutica analógica está articulada con base en el concepto de la analogía. La analogía no es mera semejanza, sino que es una semejanza en la que puede predominar la diferencia y, sin embargo, no renuncia a tender hacia la identidad, a pesar de que sabe que nunca alcanzará a esta última (pues llegar a la identidad plena con otra cosa es fundirse en ella, desaparecer) (Beuchot Perfiles 72).

La analogía es, ante todo, un modo de significación, en el que los significados de un significante se relacionan con él de manera en parte igual y en parte diferente, predominando la diferencia. La ana- 
logía se coloca entre la univocidad y la equivocidad; la univocidad es la significación completamente idéntica y sin diferencia alguna, el reino de lo claro y lo distinto; la equivocidad es la significación completamente diferente y sin posibilidad de conmensuración, el reino de lo oscuro y lo confuso, de la ambigüedad sin límite. Por eso podríamos decir que la analogía es poner límites a la univocidad (para que no se pretenda el rigor que no es alcanzable en la significación) y a la equivocidad (para que la significación no se nos derrumbe en el sinsentido).

De este modo, una hermenéutica analógica no pretenderá, como lo hace una hermenéutica unívoca, una interpretación cabal y completamente inequívoca; admitirá que siempre, al interpretar, se incurre en cierta subjetividad y ambigüedad; mas no por eso caerá en el relativismo excesivo de la hermenéutica equívoca, para la cual es imposible alcanzar el significado suficiente, y siempre habrá un exceso de pérdida, un empobrecimiento irreparable. Está, pues, entre las dos, entre esos dos extremos, entre esos dos opuestos, llevándolos a una cierta conmensuración, a un cierto equilibrio, a una cierta armonía. No en balde analogía significa, en griego, proporción, y esta palabra fue introducida en la filosofía por los pitagóricos (Beuchot Tratado 94).

Veremos que una hermenéutica así, una hermenéutica analógica, podrá ayudarnos a interpretar el símbolo, el cual tiene, según Paul Ricoeur, la estructura de la metáfora (Teoría 60 ss.). Pero una hermenéutica analógica, que conjunta metáfora y metonimia como sus dos polos, será capaz de comprender, además del aspecto metafórico del símbolo, su aspecto metonímico, por el cual nos da un conocimiento de lo universal, de la realidad, así como la metonimia nos hace pasar de las partes a la totalidad.

\section{Metáfora, metonimia y analogía}

Algo muy importante en Ricoeur es que, para él, la metáfora, aunque es lingüística, tiene raíz ontológica; se funda en la participación de los entes en el ser: 
La analogía, en efecto, se mueve dentro del nivel de los nombres y los predicados; es de orden conceptual. Pero su condición de posibilidad está en otra parte, en la propia comunicación del ser. Participación es el nombre genérico dado al conjunto de soluciones aportadas a este problema. Participar es, aproximadamente, tener parcialmente lo que el otro posee o es propiamente. Por lo tanto, la búsqueda de un concepto adecuado de analogía es paralela a la búsqueda de un concepto adecuado de participación. (Metáfora 362)

Esto hunde sus raíces en la tradición platónica y aristotélica. Para el estagirita la metáfora es una de las formas de la analogía.

El propio Aristóteles define la analogía así:

Entiendo por analogía el hecho de que el segundo término es al primero como el cuarto al tercero; entonces podrá usarse el cuarto en vez del segundo o el segundo en vez del cuarto; y a veces se añade aquello a lo que se refiere el término sustituido. Así, por ejemplo, la copa es a Dionisio como el escudo a Ares; [el poeta] llamará, pues, a la copa 'escudo de Dionisio', y al escudo, 'copa de Ares'. (18-23)

En cuanto a la metáfora misma, Ricoeur dice:

1) La metáfora es un tropo, una figura del discurso que tiene que ver con la denominación. 2) Representa la amplitud o prolongación del sentido de un nombre por medio de la desviación del sentido literal de las palabras. 3) El motivo para esta desviación es la semejanza. 4) La función de la semejanza es la de fundamentar la sustitución del sentido literal -el cual podría haber sido utilizado en el mismo lugar- por el sentido figurativo de una palabra. 5) Por lo tanto, la significación sustitutiva no representa ninguna innovación semántica. Podemos traducir una metáfora, esto es, restituir el sentido literal que la palabra figurativa sustituye. En efecto, sustitución más restitución es igual a cero. 6) Ya que no representa una innovación semántica, una metáfora no proporciona ninguna nueva 
información acerca de la realidad. Es por eso por lo que puede contarse como una de las funciones emotivas del discurso. (Interpretación 61-62)

De este modo, Ricoeur centra la metáfora en el enunciado, más que en la palabra; es, por ello, una predicación, aunque impropia. Es un fenómeno predicativo, no denominativo (a diferencia de la metonimia). Ve la metáfora como algo tensional, como la tensión entre el significado literal y el significado metafórico de una expresión. Hay excedente de sentido en el enunciado trópico, no tiene una paráfrasis exacta.

La tensión produce nuevo sentido, que se vincula con el anterior por analogía.

Si la metáfora no consiste en revestir una idea con una imagen, sino que consiste en reducir la conmoción engendrada por dos ideas incompatibles, es entonces en la reducción de esta brecha o diferencia en la que la semejanza cumple un papel [...] lo que se arriesga en una expresión metafórica es la aparición del parentesco en el que la visión ordinaria no percibe ninguna relación. (Ricoeur Metáfora 64)

La excedencia de sentido deja el solo plano del sentido y lleva al de la referencia (pues el sentido es vía hacia la referencia). De hecho, según Ricoeur, el enunciado metafórico "redescribe" la realidad, tiene potencial semántico para hacerlo. Allí hay innovación semántica, la cual, "al hacer surgir una nueva pertinencia semántica sobre las ruinas del sentido literal, suscita también un objetivo referencial, merced a la abolición de la referencia correspondiente a la interpretación literal del enunciado" (204). Y es que

la otra referencia, la que buscamos, sería a la nueva pertinencia semántica lo que la referencia abolida es al sentido literal destruido por la impertinencia semántica. Al sentido metafórico correspondería una referencia metafórica, de igual manera que al sentido literal imposible corresponde una referencia literal imposible. (204) 
Ricoeur llama a esta tensión, o trabajo, "ficción heurística", pues es la función de la redescripción que se da por la transferencia de esta ficción a la realidad. Abre a una nueva dimensión de la realidad y de la verdad. Al suspender la referencia primaria al mundo objetivo del discurso descriptivo, la metáfora da un acceso distinto a ese mismo mundo, con referencia de segundo grado. No es en el mundo de las cosas a la mano, sino en el mundo de la vida.

Para Ricoeur, hay metáforas de raíz, las cuales son

metáforas que, por un lado, tienen el poder de unir las metáforas parciales obtenidas de los diversos campos de nuestra experiencia y, en esa forma, de asegurarles un cierto equilibrio. Por otro lado tienen la habilidad de engendrar una diversidad conceptual, quiero decir, un número ilimitado de interpretaciones potenciales en el nivel conceptual. Las metáforas de raíz se reúnen y se dispersan. Reúnen imágenes subordinadas y esparcen conceptos en un nivel más elevado. Son las metáforas dominantes, capaces a la vez de engendrar y organizar una red. (Interpretación 77)

Éstas llevan a modelos: "el correspondiente exacto sería, pues, la metáfora continuada" (Ricoeur Metáfora 321). Ya de suyo el símbolo tiene una estructura parecida a la de la metáfora. Pero, además, muchas veces la metáfora se basa en un símbolo. ¿Qué es el símbolo? Ricoeur nos responde lo siguiente: "Hay símbolo cuando el lenguaje produce signos de grado compuesto donde el sentido, no conforme con designar una cosa, designa otro sentido que no podría alcanzarse sino en y a través de su enfoque o intención” (Freud 18). A pesar de que tanto el símbolo como la metáfora tienen una estructura analógica, en el símbolo no se da, una comparación entre dos términos de una cuarta proporcional (A:B::C:D), sino una comparación entre dos sentidos del mismo término:

La analogía que puede existir entre el sentido segundo y el primero no es una relación que pueda yo poner en observación y considerar desde fuera; no es un argumento; lejos de 
prestarse a la formalización, es una relación adherida a sus términos; soy llevado por el sentido primero, dirigido por él hacia el segundo; el sentido simbólico está constituido en y por el sentido literal que opera la analogía dando el análogo; a diferencia de una semejanza que podríamos considerar desde afuera, el símbolo es el movimiento mismo del sentido primario que nos asimila intencionalmente a lo simbolizado, sin que podamos dominar intelectualmente la semejanza. (Freud 19)

Además, el símbolo pasa del plano del sentido al de la referencia: "conjunta dos dimensiones, aun podríamos decir que dos universos del discurso, uno lingüístico y el otro de orden no lingüístico" (Ricoeur Teoría 67).

Ricoeur insiste en el doble significado del símbolo. Tiene doble sentido y doble referencia. Una referencia anómala. Pero el símbolo está entre la razón y la vida: "La metáfora ocurre en el universo ya purificado del logos, mientras que el símbolo duda entre la línea divisoria del bios y el logos. Da testimonio del modo primordial en que se enraíza el Discurso en la Vida. Nace donde la forma y la fuerza coinciden" (72). El símbolo tiende al mundo, al mundo de la vida, tiene una fuerza ontológica. La metáfora es su fuerza epistemológica, es su mediador lingüístico. El símbolo hace a la metáfora una demanda de trabajo: "Todo indica que la experiencia simbólica pide de la metáfora un trabajo de sentido, un trabajo que aquélla parcialmente proporciona por medio de su red organizacional y sus niveles jerárquicos. Todo indica que los sistemas de símbolos constituyen una reserva de sentido cuyo potencial metafórico está por ser expresado" (78).

La metonimia es un cambio de nombre basado en la contigüidad. Es una denominación desviada, y se da en el plano de la referencia. (La metáfora está en el registro del ser, y la metonimia en el de la referencia.) La metonimia se basa en las cosas, en la realidad. La metáfora puede generar innumerables sentidos, mientras que la metonimia está restringida a lo que permiten los referentes, pues la metáfora se basa en la semejanza, y llega un momento en que, peligrosamente, todo se parece a todo; pero la metonimia está limitada, su referencia restringe sus aplicaciones. 
El símbolo tiene un aspecto metonímico, además del metafórico. Así, el símbolo tiene las dos caras de la metáfora y la metonimia. El lado metonímico del símbolo es referencial, porque tanto el símbolo como la metonimia tienen un acceso a la referencia.

Michel Le Guern señala ese elemento metonímico en el signo:

No es necesario ser historiador de la lengua para percibir en estas expresiones la representación mental del trono o la corona. No obstante, la relación que liga al trono o la corona con la condición real no se percibe ya en virtud de una analogía, incluso de una similitud de atributo dominante. Se aprecia aquí una aproximación habitual: es, pues, una relación de contigüidad la que se establece, y la utilización de las palabras 'trono' o 'corona' para designar la realeza hace intervenir el mecanismo de la metonimia. Es bien evidente que, normalmente, el rey no se sienta en el trono ni lleva la corona más que en circunstancias completamente excepcionales; así pues, la relación metonímica está fundada sobre la permanencia de una relación simbólica. El símbolo desgastado se convierte, pues, en metonimia y queda percibida su representación mental de la imagen simbólica. (50)

Según Jakobson, la metáfora es selección de paradigmas y la metonimia combinación de sintagmas (Fundamentals 53-87). La metáfora selecciona elementos análogos o semejantes en el repertorio del paradigma; en cambio, la metonimia combina (y sustituye) sintagmas. La semántica de la metáfora es paradigmática y la de la metonimia es sintagmática; la primera funciona por semejanza y la segunda por contigüidad. (La sinécdoque es puesta en la base de ambas figuras, como en el grupo $M u$, de Lieja, o se coloca en la metonimia, como para U. Eco).

Para Eco (igual que para Jakobson), los tropos son dos: metáfora y metonimia. La segunda es la principal, pues las sustituciones sémicas que generan los tropos se basan en la contigüidad. Incluso en la semejanza hay una especie de contigüidad estructural (395). Eco subsume la sinécdoque en la metonimia. Por eso quedan la metáfora 
y la metonimia, y ambas son las dos caras de la analogía. Una y otra son, pues, los dos brazos o fuerzas de una hermenéutica analógica.

\section{La metáfora en una hermenéutica analógica}

En efecto, la metáfora es una de las formas de la analogía, a saber, la analogía de proporción impropia (o metafórica). Pero hay que decir que, como ya lo señalaba el mismo Aristóteles, no toda metáfora es analógica; sin embargo, la que funciona por analogía es una de las más importantes. Por todo ello, la interpretación de la metáfora tiene que ser un aspecto relevante en una hermenéutica analógica.

Precisamente, la hermenéutica analógica nos tiene que servir en esos ámbitos de los textos donde opera la metáfora, donde hay metaforicidad. Si la proporción propia es de carácter metonímico y, como dijimos, la proporción impropia es de carácter metafórico, la analogía (que es proporción) abarca tanto la metáfora como la metonimia, sólo que de diversas maneras.

La metonimia opera por contigüidad, mientras que la metáfora opera por semejanza. Por eso, en la metáfora es más clara la presencia de la analogía. Pero también se da en la metonimia, ya que la contigüidad implica cierta semejanza. No en balde, los retóricos del Grupo $M u$, de Lieja, han pensado que el tropo fundamental es la sinécdoque, y que la metonimia y la metáfora se derivan de ese tropo fundamental. Y es que la sinécdoque es cierta analogía muy básica, que va del todo a la parte, mientras que la metonimia es una analogía derivada, que va de la parte al todo, y la metáfora es otro tipo de analogía derivada, que va de lo semejante a lo semejante.

Roman Jakobson sostenía que la metonimia y la metáfora son los pilares del discurso humano, que la metonimia funciona sobre todo en la prosa, y la metáfora sobre todo en el ámbito de lo poético (Ensayos 389). Y que la metonimia es con lo que hacemos ciencia, mientras que la metáfora es con lo que hacemos poesía. También puede decirse que, en hermenéutica, una interpretación metonímica tira a la literalidad, al sentido literal (aunque no lo alcance), y una interpretación metafórica tira a la alegoricidad, al sentido alegórico 
o simbólico. Así, el texto se ve tensionado por la interpretación metonímica y la interpretación metafórica.

Ya Paul Ricoeur había dicho que el símbolo tiene la estructura de la metáfora (Interpretación 59, 67). Por eso podemos ver con alguna claridad que el sentido simbólico es en cierta forma sentido metafórico. La interpretación que pretenda rescatar el símbolo y la alegoría ha de tener la estructura de la metáfora, deberá poseer la estructura de una interpretación metafórica.

Por eso la metáfora es importante para la hermenéutica, sobre todo para una hermenéutica analógica. Si los barrocos buscaron ardientemente lo simbólico es porque el símbolo da sentido, y ellos estaban en una época de crisis, de sinsentido: el derrumbe del humanismo y la pérdida de los antiguos valores en los comienzos de la modernidad. Por su parte, los románticos exageraron lo simbólico y lo metafórico y, aun cuando fueron grandes analogistas, usaron demasiado la analogía metafórica, y no podemos olvidar que la metáfora es el tipo de analogía que está más cerca de la equivocidad; por eso muchos de ellos cayeron en un equivocismo demasiado grande.

Pero la auténtica analogía es la que da equilibrio, la que hace oscilar entre la univocidad y la equivocidad, sin caerse en ninguna de ellas (la metonimia corre el peligro de inclinarse demasiado a la univocidad, aunque ésta parece inalcanzable). La analogía es también el difícil equilibrio entre la metonimia y la metáfora, sin deslizarse hasta la equivocidad, y pudiendo utilizar la interpretación metonímica y la metafórica en la medida en que haga falta. Según porciones o proporciones, que eso es la analogía, la hermenéutica analógica.

Una hermenéutica analógica, pues, sabe equilibrar el uso de la interpretación sin pretender interpretaciones unívocas, ni tampoco desplomarse en interpretaciones equívocas. Sabe equilibrar el uso de la interpretación metonímica y la metafórica, según lo requiera el texto, es decir, según la medida de metonimia o de metáfora que contenga y que, por ende, requiera para ser interpretado (pues lo mismo que sirve para encodificar sirve para decodificar, y si el texto fue encodificado en clave metonímica necesita más de ese tipo de interpretación, y si fue encodificado en clave metafórica requerirá 
más de ese tipo de interpretación para revelar su sentido). Y, como se ve, la interpretación metafórica tiene más presencia en ella.

\section{Hermenéutica analógica y literatura}

De esta manera tenemos una hermenéutica dispuesta para la interpretación de los textos literarios. Lejos de la hermenéutica unívoca, que pretende una interpretación exacta y exhaustiva del texto, lo cual sucede muy pocas veces, y también lejos de la hermenéutica equívo$\mathrm{ca}$, que abandona todo rigor y seriedad y se hunde en un relativismo desmedido, tenemos la posibilidad de una hermenéutica analógica que, sin abandonar la exigencia de rigor de la hermenéutica unívoca, logra la apertura de la hermenéutica equívoca, pero sin caer en ese relativismo extremo.

Además, ya que la analogía abarca la metonimia y la metáfora, la hermenéutica analógica oscila entre la interpretación metonímica y la interpretación metafórica. Como en un gradiente, que va acercándose más a la metonimia o a la metáfora según convenga al texto. Porque la naturaleza del texto es la que comanda la clase de interpretación que se ha de aplicar.

Jakobson decía que metonimia y metáfora son los dos pilares del discurso humano; sostuvo que la metonimia es más apta para la prosa y el discurso científico; y que la metáfora es más apta para el verso y el discurso poético (Fundamentals 95). En todo caso, ahí tenemos los dos polos extremos que se juegan en la literatura, y la analogía nos da la capacidad de abarcarlos a los dos y de usarlos según se requiera, otra vez de acuerdo con el género del texto.

Es la vuelta a la oscilación entre el sentido literal y el sentido alegórico, de la antigua hermenéutica. De hecho, toda la historia de la hermenéutica puede seguirse a través de la pugna, a veces a muerte, entre los literalistas y los alegoristas. Los que privilegiaban el sentido literal tendían a la univocidad; los que privilegiaban el alegórico tendían a la equivocidad, pero algunas veces se logró la mediación, el equilibrio, con un sentido simbólico o analógico. 
Esto es lo que necesitamos ahora, distendidos como estamos entre la hermenéutica univocista de los positivismos y la hermenéutica equivocista de los posmodernismos. Hay que buscar el equilibrio proporcional, el medio analógico, para poder abarcar tanto un extremo como el otro, sin descuartizarnos. Es el equilibrio proporcional de la analogía, que es la base de la phrónesis o prudencia, de los griegos, por ejemplo de Aristóteles, y que se nos presenta como muy conveniente, ahora en forma de hermenéutica, de instrumento para la interpretación.

\section{Conclusión}

La metáfora es una piedra de tropiezo para la hermenéutica (y la semiótica). Es la cruz o el experimentum crucis para ellas. Si la semiótica puede explicar la metáfora y si la hermenéutica puede interpretarla adecuadamente, ya han cumplido bastante de su cometido. La metáfora tiene su propia verdad, a pesar de no tener verdad literal, como es obvio. Y es una parte muy grande de nuestro discurso. Es lo que supo señalar Jakobson, que los dos pilares del discurso humano son la metáfora y la metonimia. Y ambas son abarcadas y abrazadas por la analogía.

Grandes analogistas fueron los barrocos, que tanta importancia dieron al símbolo. Precisamente porque el símbolo es analógico, se interpreta por analogía. Los románticos también fueron grandes analogistas y usaron la analogía junto con la ironía, como para mitigarla, para que no se hiciera sarcasmo, herida rabiosa, y perdiera su auténtico significado. Es lo que ahora parecemos necesitar: una sensibilidad para la analogía, que nos saque del callejón sin salida de la pretensión univocista y la decepción equivocista.

Por eso he querido señalar en esta conferencia la utilidad que puede tener una hermenéutica analógica, esto es, una herramienta interpretativa que esté basada en la analogía, en ese concepto que abarca y modula la metonimia y la metáfora, el sentido literal y el sentido alegórico, que oscila entre la exigencia de rigor de la hermenéutica unívoca y la apertura de la hermenéutica equívoca, que a 
veces son desmedidas y dañan la interpretación, pero que se pueden equilibrar proporcionalmente, en lo cual consiste el pensamiento analógico. Él nos abrirá caminos nuevos, en esta crisis cultural, en este impasse en el que nos encontramos en la filosofía y en la literatura, para salir a terrenos más promisorios. Porque ya se nota un cansancio severo en muchos de nuestros pensadores. Es la vida del intelecto y de la imaginación, que se manifiesta en sus aspiraciones.

\section{Bibliografía}

Aristóteles. Poética 21, 1457b.

Beuchot, Mauricio. Perfiles esenciales de la hermenéutica. 5a. ed. México: FCE-UNAM, 2008.

- Tratado de hermenéutica analógica. Hacía un nuevo modelo de la interpretación. 4ta. ed. México: UNAM-Ítaca, 2008.

Eco, Umberto. Tratado de semiótica general. Barcelona: Lumen, 2000. Jakobson, Roman and M. Halle. Fundamentals of Language. 2a. ed. The Hague-Paris: Mouton, 1970.

Jakobson, Roman. "Lingüística y poética". Ensayos de lingüistica general. México: Origen-Planeta, 1986.

Le Guern, M. La metáfora y la metonimia. Madrid: Cátedra, 1990.

Ricoeur, Paul. Frend una interpretación de la cultura. México: Siglo XXI, 1990.

Ricoeur, Paul. Teoría de la interpretación. Discurso y excedente de sentido. México: Siglo XXI-UIA, 1995.

—. La metáfora viva. Madrid: Trotta, 2001. 